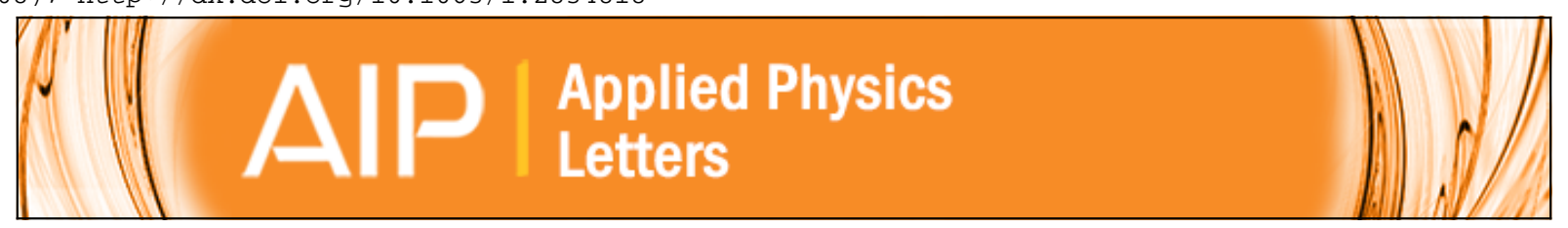

Millisecond switching in solid state electrochromic polymer devices fabricated from ionic self-assembled multilayers

Vaibhav Jain, Hank M. Yochum, Reza Montazami, and James R. Heflin

Citation: Applied Physics Letters 92, 033304 (2008); doi: 10.1063/1.2834818

View online: http://dx.doi.org/10.1063/1.2834818

View Table of Contents: http://scitation.aip.org/content/aip/journal/apl/92/3?ver=pdfcov

Published by the AIP Publishing 


\title{
Millisecond switching in solid state electrochromic polymer devices fabricated from ionic self-assembled multilayers
}

\author{
Vaibhav Jain \\ Macromolecular Science and Engineering, Virginia Tech, Blacksburg, Virginia, 24061, USA \\ Hank M. Yochum \\ Department of Physics and Engineering, Sweet Briar College, Sweet Briar, Virginia 24595, USA \\ Reza Montazami and James R. Heflin ${ }^{\text {a) }}$ \\ Department of Physics, Virginia Tech, Blacksburg, Virginia 24061, USA
}

(Received 11 June 2007; accepted 20 December 2007; published online 24 January 2008)

\begin{abstract}
The electrochromic switching times of solid state conducting polymer devices fabricated by the ionic self-assembled multilayer method has been investigated. The devices were composed of bilayers of poly(3,4-ethylenedioxythiophene): poly(styrenesulfonate) and poly(allylamine hydrochloride) on indium tin oxide substrates. Devices fabricated from 40 bilayer thick films have coloration and decolaration switching times of 31 and $6 \mathrm{~ms}$, respectively, with low applied voltage $(1.4 \mathrm{~V})$ for an active area of $0.6 \mathrm{~cm}^{2}$. The switching times have been shown to decrease with the active area of the electrochromic device suggesting that even faster electrochromic switching times are possible for devices with smaller areas. (C) 2008 American Institute of Physics.
\end{abstract}

[DOI: $10.1063 / 1.2834818]$

Electrochromic (EC) devices show a reversible color change upon reduction or oxidation of the electrochromic material by application of a voltage. Tungsten oxide electrochromic devices have been used in smart windows, automotive rear-view mirrors, and thin passive displays for more than a decade, but electrochromic materials have not yet been employed in fast displays because of their slow colorswitching response time, typically on the order of seconds. A large number of conducting polymers exhibit electrochromic behavior, including polyaniline, polyviologens, and polypyrrole, but poly(3,4-ethylenedioxythiophene:poly (styrenesulfonate) (PEDOT:PSS) has been preferred in electrochromic studies because of its easy processability, high conductivity $(300 \mathrm{~S} / \mathrm{cm})$, high contrast at low voltage, and long term stability without degradation as compared to other conducting polymers. ${ }^{1-4}$ Here, we demonstrate fast switching response time $(<10 \mathrm{~ms})$ of electrochromic devices consisting of PEDOT:PSS and poly(allyamine hydrochloride) (PAH) multilayered films fabricated by the ionic selfassembled multilayer (ISAM) approach.

The electrochromic properties of PEDOT:PSS have been studied by several groups. Delongchamp et al. fabricated solid state dual electrochromic PEDOT and polyaniline ISAM films which had switching speeds $\left(t_{75 \%}\right)$ of $0.37 \mathrm{~s}$ for decoloration and $1.22 \mathrm{~s}$ for coloration. Kumar et al. found that PEDOT:PSS films made by electropolymerization have switching speeds of several seconds for thicknesses of $300 \mathrm{~nm} .{ }^{5}$ Cho et al. have shown that PEDOT nanotubes fabricated in an intricate process of laying out an array structure on indium tin oxide (ITO) with a silica template have very fast reflectivity changes of $8.8 \mathrm{~ms}$ coloration and $3.5 \mathrm{~ms}$ decoloration for nanotubes of $20 \mathrm{~nm}$ wall thickness with $-1 \mathrm{~V}-+1 \mathrm{~V}$ applied for a reflectivity change of $25 \%$. $^{6} \mathrm{We}$ report PEDOT electrochromic devices that operate at comparable switching rates as reported by Cho et al. and can be

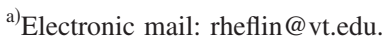

made with the fairly simple and inexpensive ISAM approach with readily available conducting electrodes and materials.

ISAM films are formed by a layer-by-layer deposition technique $^{7}$ that provides highly precise, nanometer-scale films on the electrode surface. ISAM films have been used for a variety of applications, ${ }^{8}$ for example, in nonlinear optics, ${ }^{9,10}$ optical sensors, ${ }^{11}$ light-emitting diodes, ${ }^{12}$ and photovoltaics. ${ }^{13,14}$ ISAMs have also been used in the fabrication of a variety of electrochromic films, including PEDOT, but the PEDOT devices did not have the fast switching times reported here. ${ }^{2}$ The ISAM technique allows the possibility of choosing a wide range of electrochromic materials that can be used in combination with PEDOT for dual and multihue electrochromic devices. ${ }^{1}$

The ISAM technique involves dipping a charged substrate alternately in aqueous polycation and polyanion solutions. We have used glass slides coated with ITO as our substrate, PAH as the cationic polymer, and PEDOT:PSS as the anionic polymer. Symmetric solid state devices were fabricated by sandwiching together two ITO slides coated with PEDOT/PAH bilayers using a transparent conducting gel poly(2-acylamido 2-methyl propane sulfonic acid). The device structure is shown in the inset of Fig. 1. We used $10 \mathrm{mM}$ PAH (Sigma-Aldrich) at $p \mathrm{H} 4$ and PEDOT:PSS (BaytronP) has been prepared by the method described by Delongchamp et al. ${ }^{1}$ The area of the electrochromic device was controlled by appropriately etching the ITO substrates to create stripes or pixels of the desired size. Cyclic voltammetry, not shown here, of a (PAH/PEDOT:PSS $)_{40}$ film shows a broad reduction peak of the PEDOT and is consistent with the measurements of Tang et $a l .^{3}$ The diffusion coefficient $\left(D_{e} \sim 2.82\right.$ $\times 10^{-8} \mathrm{~cm}^{2} / \mathrm{s}$ ) value calculated by the Randles-Sevick equation,

$$
I_{p}=\left(2.69 \times 10^{5}\right) n^{3 / 2} A D_{e}^{1 / 2} C \nu^{1 / 2},
$$

where $I_{p}=321 \mathrm{~mA}$ is the cathodic peak current, $n=1$ is the electron stoichiometry, $A=1$ is the electrode area $\left(\mathrm{cm}^{2}\right)$, 


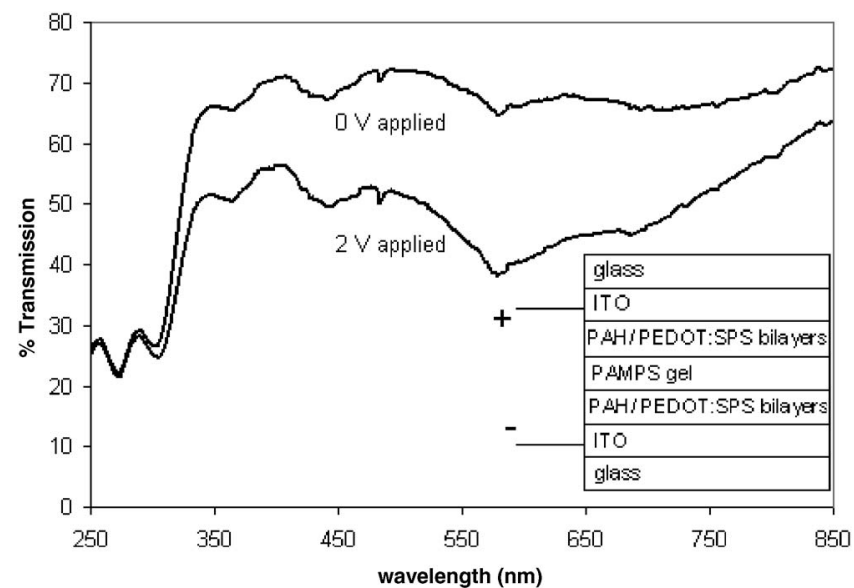

FIG. 1. Percentage transmission vs wavelength of an electrochromic device consisting of two PAH/PEDOT 80 bilayer films with 2.0 and $0 \mathrm{~V}$ applied.

$C=0.01$ is the concentration of electrolyte $\left(\mathrm{mol} / \mathrm{cm}^{3}\right)$, $\nu=0.5$ is the scan rate $(\mathrm{V} / \mathrm{s})$.

Symmetric PEDOT EC devices in which one of the PEDOT layers acts as a conductive electrode material have been demonstrated by Mecerreyes et al. ${ }^{15}$ In the present work, a completely symmetric and reversible PEDOT EC device has been demonstrated on ITO electrodes such that, dependent upon the polarity of the applied voltage, only the PEDOT film connected to the negative terminal exhibits a color change.

The transmission spectrum of the (PAH/PEDOT:PSS $)_{80}$ (consisting of two 80 bilayer films) device is presented in Fig. 1 at $0 \mathrm{~V}$ and with $2 \mathrm{~V}$ applied, as measured with a Filmetrics F20 UV-vis spectrometer. The color change is between very pale blue and dark blue. The maximum change in transmittance between 0 and $2 \mathrm{~V}$ is $35 \%$ at $580 \mathrm{~nm}$. The temporal response of the devices was monitored with a $\mathrm{He}-\mathrm{Ne}$ laser and photodiode as a square wave voltage $(0-1.4 \mathrm{~V})$ was applied to the electrochromic device. Figure 2 shows the electrochromic film response as well as the applied square wave voltage signal for a 40 bilayer (two 40 bilayer films) $1 \mathrm{~cm}^{2}$ area PAH/PEDOT device. Figure 3 shows the fast electrochromic time response of coloration and decoloration of the $0.6 \mathrm{~cm}^{2}$ (PAH/PEDOT:PSS) 40 device. The coloration and decoloration times (to $90 \%$ of equilibrium value) are $31 \mathrm{~ms}$ and $6 \mathrm{~ms}$, respectively. We note

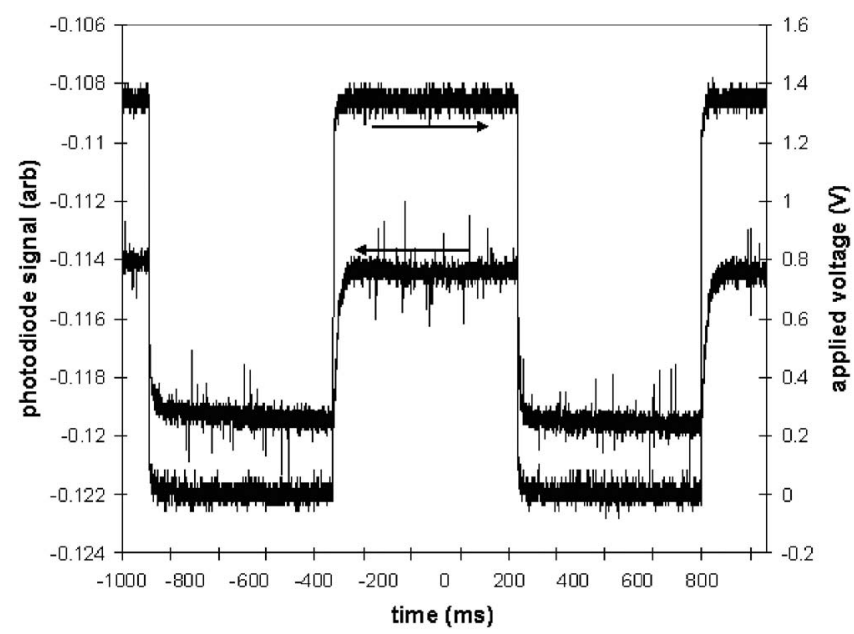

FIG. 2. Photodiode signal vs time with square wave voltage applied for a device consisting of two 40 bilayer films with $1 \mathrm{~cm}^{2}$ area.
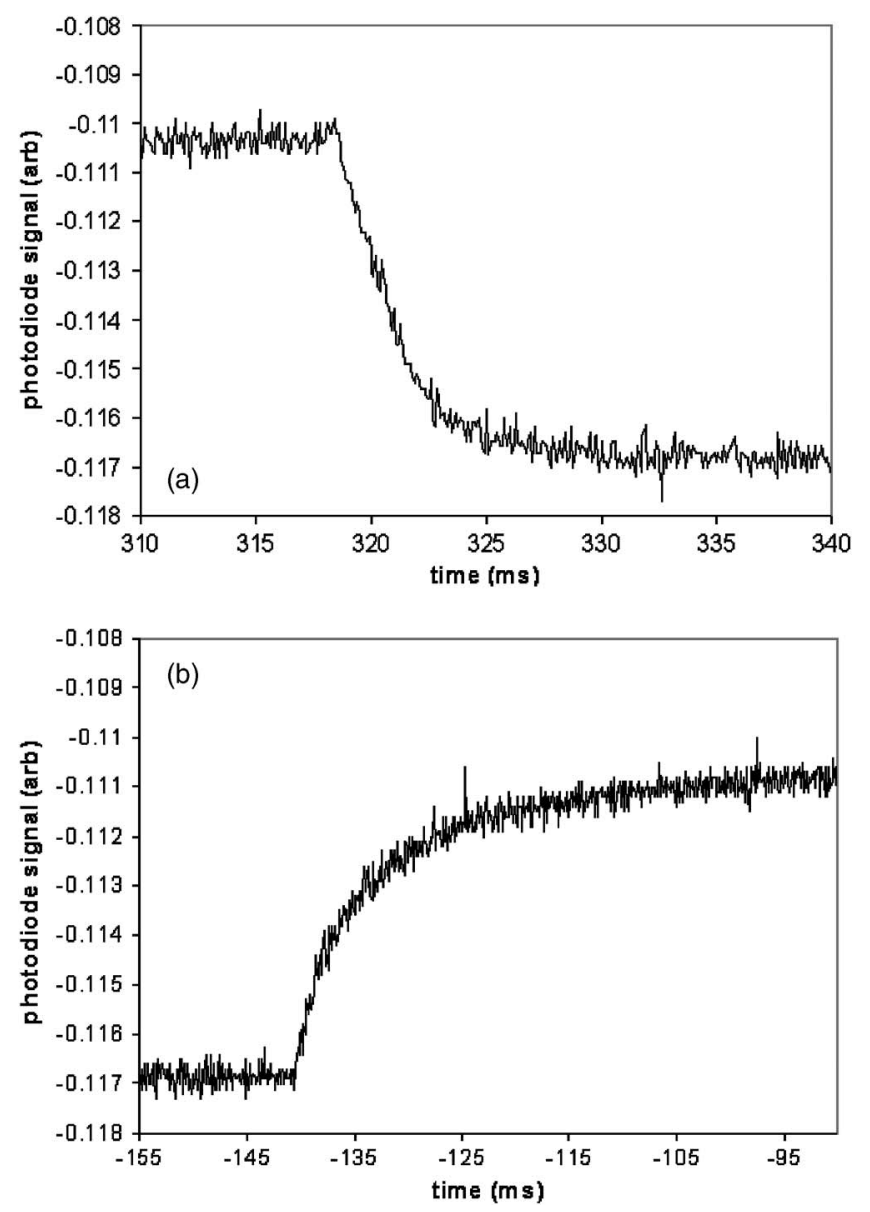

FIG. 3. Decoloration (a) and coloration (b) of a $0.6 \mathrm{~cm}^{2}$ device consisting of two 40 bilayer PAH/PEDOT films with applied voltage of $0-1.4 \mathrm{~V}$.

that the decoloration time is shorter than the coloration time for these devices, as has been previously observed. ${ }^{1}$ In addition, the coloration and de-coloration times of a 20 bilayer of $1 \mathrm{~cm}^{2}$ device are approximately 20 and $8 \mathrm{~ms}$, respectively, indicating that thinner devices switch faster, as would be expected due to the decreased transit time for the ionic motion. The contrast associated with our switching experiments at $633 \mathrm{~nm}$, which is not the wavelength of maximum contrast, is approximately $8 \%$ and $5 \%$ for 40 bilayer and 20 bilayer, devices, respectively.

In Fig. 4, we show the relationship between switching speed $\left(t_{90 \%}\right)$ and the area of device, where $t_{90 \%}$ is the time for the film to achieve $90 \%$ of its full electrochromic response. The film response time decreases linearly with the active area of the device, similar to the response of a $R C$ circuit. Pixel areas associated with active displays are often $<0.05 \mathrm{~cm}^{2}$. The relationship in Fig. 4 suggests that switching times for $0.05 \mathrm{~cm}^{2}$ area devices should be on the order of $3 \mathrm{~ms}$ for coloration and $0.6 \mathrm{~ms}$ for decoloration. It is anticipated that a combination of smaller area and increased polymer thickness can, thus, provide for very fast switching and significantly higher contrast than that measured here.

We have demonstrated the fast switching of an ionic self-assembled multilayer solid-state polymer electrochromic device compatible with flat-panel display rates. Devices consisting of two 80 bilayer PAH/PEDOT films display a maximum contrast of $35 \%$ at $580 \mathrm{~nm}$. Devices with an active area of $0.6 \mathrm{~cm}^{2}$ made from two 40 bilayer (400 nm thick) films show coloration and decoloration times of 31 and $6 \mathrm{~ms}$, respectively, with a linear scaling of the switching speed with 


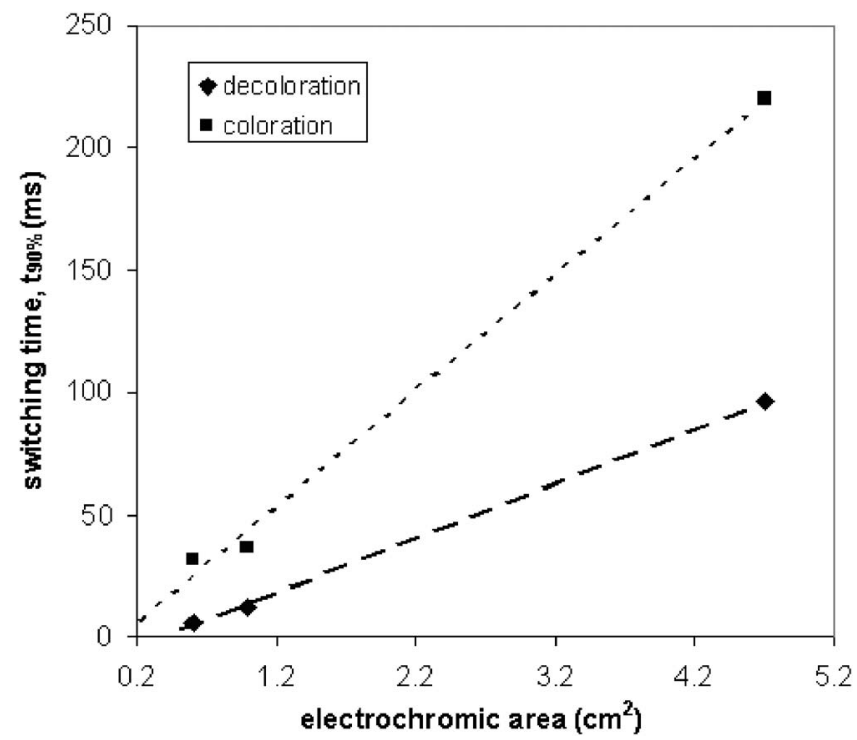

FIG. 4. Decoloration and coloration switching times vs electrochromic device area for devices consisting of two 40 bilayer PEDOT films. Lines shown to guide the eye.

the active area of the device. The fast switching is obtained through the combination of a number of factors: fabrication of thin, homogeneous films by self-assembly that have a large diffusion coefficient and short distance required for ionic motion, use of the symmetric quasisolid state geometry with a thin layer of electrolyte gel, and recognition of the dependence of the response time on device area. These results suggest that ISAM electrochromic devices are potential candidates for next-generation flat-panel displays.
H.M. Yochum acknowledges support from the Sweet Briar College Faculty Fellowship. This material is based upon work supported in part by the U.S. Army Research Office under Grant No. W911NF-07-1-0452 Ionic Liquids in Electro-Active Devices (ILEAD) MURI.

${ }^{1}$ D. M. Delongchamp, M. Kastantin, and P. T. Hammond, Chem. Mater. 15, 1575 (2003).

${ }^{2}$ D. M. Delongchamp and P. T. Hammond, Adv. Mater. (Weinheim, Ger.) 13, 1455 (2001).

${ }^{3}$ Z. Tang, S. T. Donohoe, J. M. Robinson, P. A. Chiarelli, and H. Wang, Polymer 46, 9043 (2005).

${ }^{4}$ A. L. Holt, J. M. Leger, and S. A. Carter, Appl. Phys. Lett. 86, 123504 (2005).

${ }^{5}$ A. Kumar, D. M. Welsh, M. C. Morvant, F. Piroux, K. A. Abboud, and J. R. Reynolds, Chem. Mater. 10, 896 (1998).

${ }^{6}$ S. I. Cho, W. J. Kwon, S.-J. Choi, P. Kim, S.-A. Park, J. Kim, S. J. Son, R. Xiao, S.-H. Kim, and S. B. Lee, Adv. Mater. (Weinheim, Ger.) 17, 171 (2005).

${ }^{7}$ G. Decher, Science 277, 1232 (1997).

${ }^{8}$ P. T. Hammond, Adv. Mater. (Weinheim, Ger.) 16, 1271 (2004).

${ }^{9}$ J. R. Heflin, C. Figura, D. Marciu, Y. Liu, and R. Claus, Appl. Phys. Lett. 74, 495 (1999).

${ }^{10}$ J. R. Heflin, M. T. Guzy, P. J. Neyman, K. J. Gaskins, C. Brands, Z. Wang, H. W. Gibson, R. M. Davis, and K. E. Van Cott, Langmuir 22, 5723 (2006).

${ }^{11}$ Z. Wang, J. R. Heflin, R. H. Stolen, and S. Ramachandran, Appl. Phys. Lett. 86, 223104 (2005).

${ }^{12}$ O. Onitsuka, A. C. Fou, M. Ferreira, B. R. Hsieh, and M. F. Rubner, J. Appl. Phys. 80, 4067 (1996).

${ }^{13}$ H. Mattoussi, M. F. Rubner, F. Zhou, J. Kumar, S. K. Tripathy, and L. Y. Chiang, Appl. Phys. Lett. 77, 1540 (2000).

${ }^{14}$ J. K. Mwaura, M. R. Pinto, D. Witker, N. Ananthakrishnan, K. S. Schanze, and J. R. Reynolds, Langmuir 21, 10119 (2005).

${ }^{15}$ D. Mecerreyes, R. Marcilla, E. Ochoteco, H. Grande, J. P. Pomposoa, R. Vergaz, and J. M. Sánchez Pena, Electrochim. Acta 49, 3555 (2004). 